\title{
Malformación linfangiomatosa intestinal con tejido pancreático ectópico. A propósito de un caso y revisión de la literatura
}

Dra. Selena Torga $S^{(1)}$, Lucía Raposo $R^{(1)}$, Esther Yagüe $Z^{(1)}$, Nataliz Vega $M^{(2)}$.

1. Servicio de Radiodiagnóstico del Hospital El Bierzo, Ponferrada, España.

2. Servicio de Pediatría del Hospital Central de Asturias, Oviedo, España.

Intestinal lymphangiomatosis with ectopic pancreatic tissue: A case report and literature review

Abstract. Intestinal lymphangiomatosis is a rare malformation typically affecting children. Its etiology is unknown, although several hypotheses have been proposed. We present a case of intestinal lymphangiomatosis with ectopic pancreatic tissue of the mesentery, an association not previously described in literature. We emphasize the fact that this entity has sometimes been associated with other intra-abdominal malformations, even conditions undescribed in scientific literature. It must be considered the first differential diagnosis for pediatric patients with radiological evidence of mesenteric cystic lesions, subsequently confirmed by pathological examination.

Keyword: Abdominal pain, Intestinal Lymphangiectasis, Lymphangiomatosis, Mesentery.

Resumen. La malformación linfangiomatosa intestinal es una entidad poco frecuente, típica de la edad pediátrica, cuya etiopatogenia es desconocida, aunque se barajan varias hipótesis.

Presentamos un caso de linfangiomatosis intestinal con tejido pancreático ectópico mesentérico, una asociación no descrita anteriormente en la literatura. Destacamos la importancia de conocer que esta entidad, en ocasiones, se asocia a otro tipo de malformaciones intrabdominales, incluso no descritas previamente en la literatura. Se debe plantear como el primer diagnóstico diferencial durante la edad pediátrica, ante el hallazgo radiológico de lesiones quísticas mesentéricas, confirmando posteriormente mediante un estudio anatomopatológico de las lesiones.

Palabras clave: Dolor abdominal, Linfangiomatosis, Linfangiectasia intestinal, Mesenterio.

Torga S, et al. Malformación linfangiomatosa intestinal con tejido pancreático ectópico. A propósito de un caso y revisión de la literatura. Rev Chil Radiol 2012; 18(2): 70-72.

Correspondencia: Dra. Selena Torga S. / selenatorga@hotmail.com

Trabajo recibido el 16 de marzo de 2012, aceptado para publicación el 22 de mayo de 2012.

Introducción

Los linfangiomas múltiples del tracto gastrointestinal son una patología infrecuente, típica de la edad pediátrica. La presentación más común es distensión abdominal y masa palpable, estando los pacientes asintomáticos en la mayor parte de los $\operatorname{casos}^{(1-3)}$.

Presentamos el caso de un paciente pediátrico con linfangiomatosis del intestino delgado asociado a la presencia de tejido pancreático ectópico mesentérico, entidad no descrita previamente en la literatura.

\section{Caso clínico}

Paciente de 8 años de sexo femenino, sin antecedentes de interés. Consulta en el servicio de urgencias por dolor abdominal difuso de 48 horas de evolución y distensión abdominal. En el examen físico la paciente se encuentra afebril y muestra un buen estado general.

Se realiza ecografía abdominal, demostrándose múltiples masas quísticas avasculares y sin conexión aparente entre ellas, que parecen depender del mesenterio. Se realiza tomografía computada de abdomen con contraste intravenoso, observando grandes masas hipodensas multiloculadas, bien definidas y de paredes finas, que no muestran realce de contraste y se localizan en el mesenterio, meso ileocecal y en la pelvis. El diámetro de las lesiones varía entre 1 y $4 \mathrm{~cm}$. Las lesiones descritas condicionan un engrosamien- 
to mural de varios segmentos de intestino delgado, que estenosan mínimamente la luz, sin signos de obstrucción del tránsito. En el mesenterio también se identifican tres lesiones focales hipercaptantes de 12 $\mathrm{mm}$ y una calcificación puntiforme difusa (Figura 1).

En la resonancia magnética con contraste intravenoso realizada se confirma la naturaleza quística de las masas multiloculadas, así como la ausencia de componentes adiposos. Se confirma la presencia de tres lesiones sólidas nodulares dispersas en el mesenterio (Figura 2).

La paciente fue tratada con excisión quirúrgica completa de las masas quísticas y parcial, del meso del intestino delgado afecto (Figura 3).

El diagnóstico anatomopatológico de las lesiones fue de linfangiomatosis múltiple intestinal con presencia de tejido pancreático ectópico.

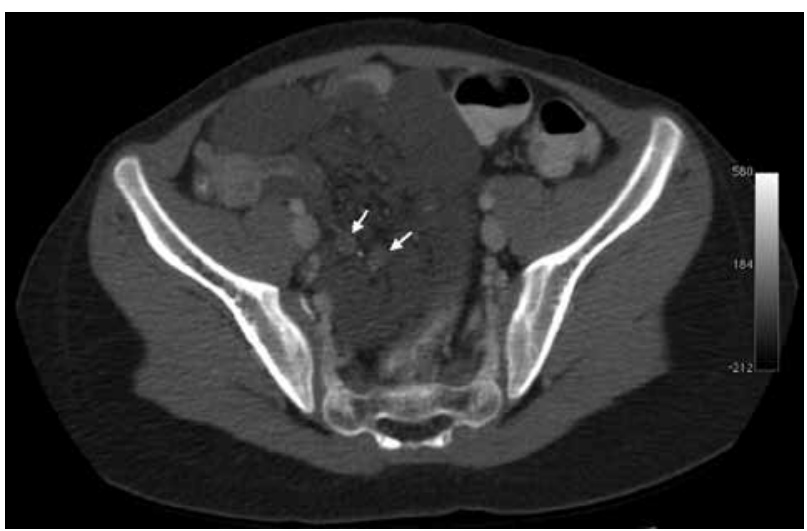

Figura 1a. TC corte axial demostrando masas hipodensas multiloculadas que no captan tras la administración de contraste. Se identifican dos de las lesiones nodulares hipercaptantes mesentéricas (flechas).

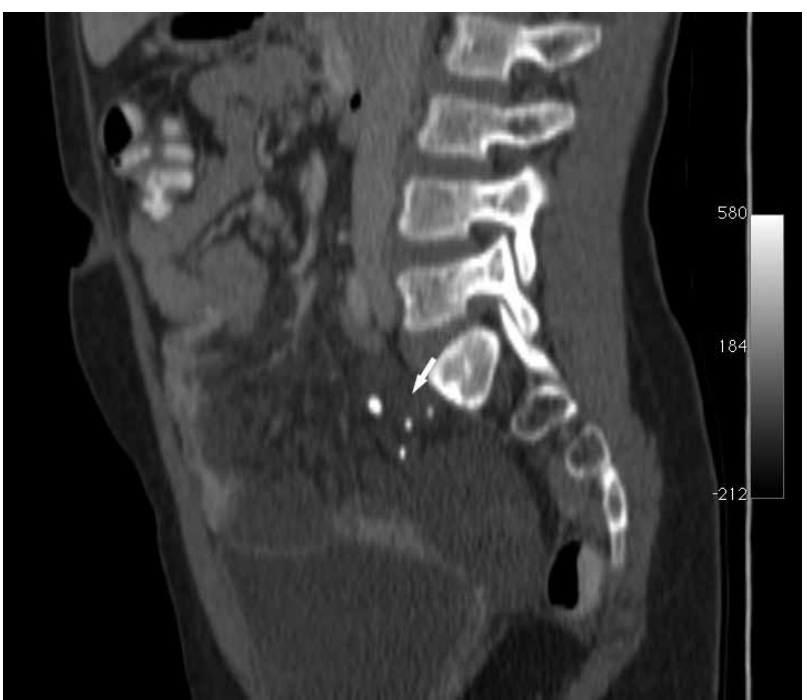

Figura 1b. TC reconstrucción sagital demostrando la calcificación puntiforme difusa mesentérica (flecha).

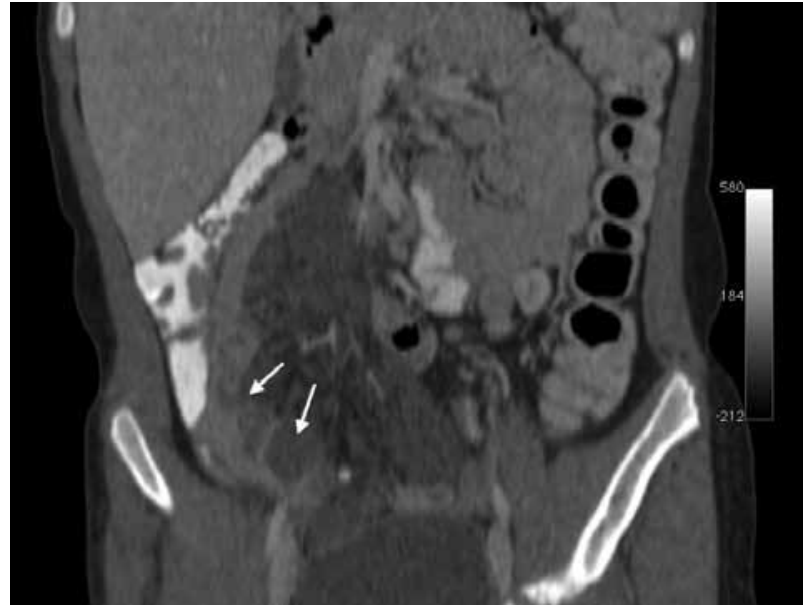

Figura 1c. TC reconstrucción coronal demostrando el engrosamiento mural de algunos segmentos de intestino delgado (flechas).

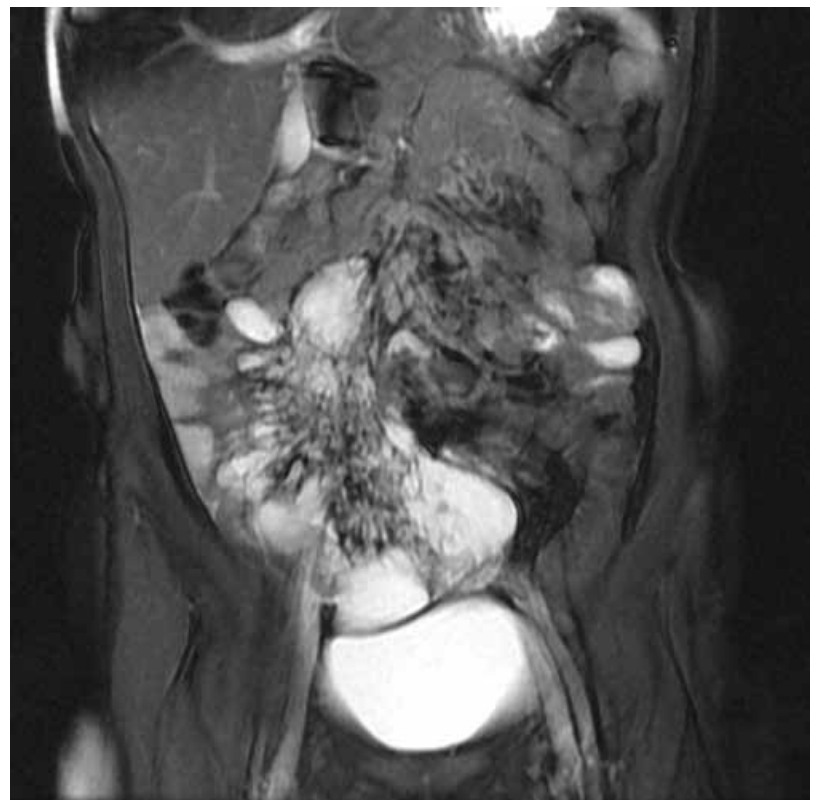

Figura 2. RM secuencia FIESTA coronal donde se observan las masas quísticas múltiples localizadas en el mesenterio, meso ileocecal y en la pelvis.

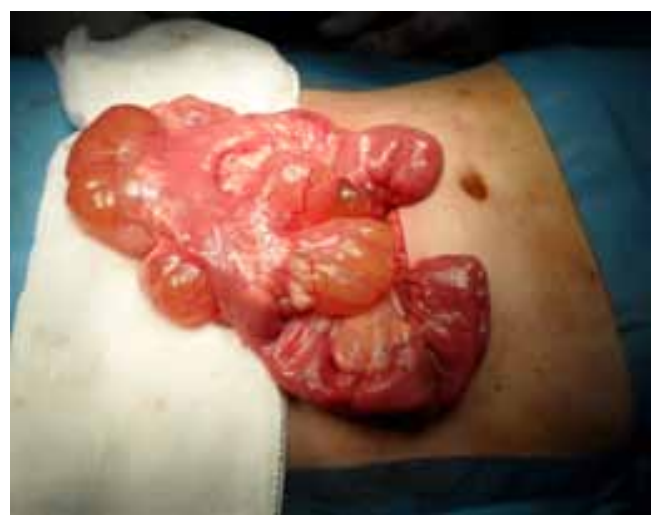

Figura 3. Demostración fotográfica quirúrgica donde se observan las lesiones quísticas múltiples adyacentes al yeyuno-íleon. 


\section{Discusión}

La linfangiomatosis quística intestinal es una entidad infrecuente, con una prevalencia de 5-6\% de todos los tumores benignos pediátricos. Dentro del espectro de las malformaciones linfangiomatosas que afectan a la edad pediátrica el $90 \%$ se localiza en cabeza, cuello y axila, mientras que el $10 \%$ restante muestra una localización intrabdominal ${ }^{(1-3)}$.

Pueden ser adquiridas o congénitas, siendo la etiología desconocida en este último grupo. Se barajan varias hipótesis y la teoría más aceptada actualmente para el origen congénito de esta enfermedad es la existencia de una alteración en el desarrollo linfático intestinal. El mecanismo patogénico es la ausencia de comunicación entre el tejido linfático del intestino delgado y los vasos linfáticos principales durante el desarrollo fetal, situación que da lugar a la formación de espacios quísticos revestidos de endotelio(1,4).

La presentación más común es distensión abdominal y masa palpable, aunque también pueden presentar dolor abdominal, náuseas y vómitos ${ }^{(5)}$.

Las complicaciones más frecuentes descritas en esta patología son: obstrucción de intestino delgado compresiva por linfangiomas gigantes ${ }^{(1)} ;$ y vólvulo de intestino delgado que puede condicionar un cuadro obstructivo mecánico intestinal(2).

Los hallazgos por imagen frecuentes son lesiones quísticas múltiples o únicas, no captantes y un engrosamiento mural del tracto gastrointestinal afecto $^{(3,5-7)}$. Puede asociarse una calcificación puntiforme mesentérica, cuyo mecanismo patogénico es desconocido, aunque existen muy pocos casos en la literatura que presenten este hallazgo ${ }^{(4,5)}$. No hemos encontrado en la literatura ningún caso que tuviera componentes sólidos mesentéricos.

En nuestro caso, tras el análisis anatomopatológico se confirmó que las tres lesiones sólidas nodulares identificadas tanto en la TC como en RM, se trataban de tejido pancreático ectópico localizado en el mesenterio. Esta asociación no ha sido descrita previamente en la literatura, aunque si se han descrito casos de otras malformaciones asociadas como hemangiomas esplénicos y malformaciones vasculares en el tracto intestinal(4).

La existencia de componentes sólidos en el mesenterio dificultó el diagnóstico radiológico, planteando el diagnóstico diferencial entre la linfangiomatosis intestinal con hallazgos atípicos, el leiomioma/leiomiosarcoma quístico, el teratoma quístico maduro, pseudoquistes y otras lesiones quísticas mesentéricas congénitas (quistes de duplicación intestinal, quiste entérico y quiste mesotelial) ${ }^{(6,8-10)}$. El leiomiosarcoma quístico se caracteriza por la presencia de una lesión quística con contenido hemorrágico-necrótico, que se localiza más frecuentemente en el intestino delgado, sin nódulos sólidos ni calcificaciones. El teratoma quístico es un tumor que presenta componentes sólidos, quísticos y calcificaciones, aunque éstas suelen ser groseras y de mayor tamaño que las que aparecen en nuestro caso. Tanto los pseudoquistes como las lesiones quísticas mesentéricas congénitas, son lesiones quísticas bien definidas, sin componentes sólidos ni calcificaciones y habitualmente únicas.

\section{Conclusión}

La linfangiomatosis intestinal es un diagnóstico relativamente frecuente en la edad pediátrica y será el primer diagnóstico diferencial a plantear ante el hallazgo radiológico de lesiones quísticas mesentéricas múltiples. Se debe tener presente que esta entidad puede asociarse a otras malformaciones intrabdominales, que incluso no hallan sido descritas previamente en la literatura. Es de vital importancia confirmar los hallazgos en este tipo de patología con un análisis anatomopatológico de las lesiones.

\section{Bibliografía}

1. Méndez R, Solar A, Gómez M, Somoza I. Giant mesenteric cystic lymphangioma in an infant presenting with acute bowel obstruccion. J Can Chir. 2009; 52.

2. Day W, Kan D. A small bowel lymphangioma presenting as a volvulus. Hong Kong Med J. 2010; 16.

3. Pickhardt P, Bhalla S. Primary Neoplasms of Peritoneal and Sub- peritoneal Origin: CT Findings. RadioGraphics 2005; 25: 983-995.

4. Zhu H,Yuan Z, Zhu X, Shi B, Upadhyaya M, Chen K. Gastrointestinal tract lymphangiomas: findings at $\mathrm{CT}$ and endoscopic imaging with histopathologic correlation. Abdom Imaging 2008; 33: 662-668.

5. Hamrick J, Chiechi M, Abbitt P, Ros P. Neoplastic and Inflammatory Processes of the Pentoneum, Omentum and Mesentery: Diagnosis with CT. RadioGraphics 1992; 12: 1051-1068.

6. Won S, Myung J, Lee J, Ro K, Won J, Phil H, Young K. A Case Report with Lymphangiomatosis of the Colon. J Korean Med Sci 2010; 25: 155-158.

7. Stoupis C, Ros P, Abbit P, Burton S, Gauger J. Bubbles in the Belly: Imaging of Cystic Mesenteric or Omental masses. RadioGraphics 1994; 14: 729-737.

8. Buonomo C, Griscom T. Pediatric Case of the Day. Radiographics 1991; 11: 1146-1148.

9. Castillo S, Vargas B, Rodríguez M. Quistes primarios mesentéricos y omentales: hallazgos en imagen. Radiología 2004; 46: 29-33.

10. Lohrmanna C, Foeldib E, Langera M. Assessment of the lymphatic system in patients with diffuse lymphangiomatosis by magnetic resonance imaging. Eur J Radiol 2011; 80: 576-581. 